\title{
Manufacture and Characteristics of Oil-Modified Refined Lacquer for Wood Coatings
}

\author{
Chia-Wei Chang ${ }^{\circledR}$, Hsiu-Ling Lee and Kun-Tsung Lu * \\ Department of Forestry, National Chung Hsing University, 250, Kuo-Kuang Rd., Taichung 402, Taiwan; \\ dimmerc@hotmail.com (C.-W.C.); er4545er4545@yahoo.com.tw (H.-L.L.) \\ * Correspondence: lukt@nchu.edu.tw; Tel.: +886-4-2284-0345 (ext. 122); Fax: +886-4-2287-3628
}

Received: 17 October 2018; Accepted: 25 December 2018; Published: 26 December 2018

\begin{abstract}
Oriental lacquer, a natural and renewable polymeric coating, comes from the sap produced by lacquer trees. For practical applications, oriental lacquer must be refined to reduce its water content and enhance its quality. In this study, drying oils were blended with oriental lacquer during a refining process to produce oil-modified refined lacquer (OMRL). Rhus succedanea lacquer, composed of $54.1 \%$ urushiols, $34.3 \%$ water, $7.2 \%$ plant gum, and $4.4 \%$ nitrogenous compounds, and drying oils, including tung oil (TO), linseed oil (LO), and dehydrated castor oil (DCO), were used as materials in this study. The effect of type and amount $(0 \%, 10 \%$, and $20 \%$ by wt $\%)$ of drying oils added to lacquer on lacquer properties were evaluated. Results show that the drying oils acted as a diluent, which reduced the viscosity, and enhanced workability, shortened touch-free drying time and accelerated the hardened drying of the OMRL. The results also indicated that the hardness, mass retention, $T_{\mathrm{g}}$, tensile strength, abrasion resistance, and lightfastness of OMRL films decreased as more drying oils were blended with lacquer. Conversely, the bending resistance, elongation at break, impact resistance increased. Gloss was greatly improved through the blending of more drying oils with lacquer. In conclusion, the LO-modified refined lacquer (RL) had the highest film gloss and the DCO-modified RL had the shortest drying time for coating. Otherwise, the film properties were similar among the three types of drying oils.
\end{abstract}

Keywords: oriental lacquer; oil-modified refined lacquer; drying oil; blending; wood coating

\section{Introduction}

Oriental lacquer, a natural and renewable polymeric coating, comes from the sap collected from Rhus succedanea lacquer trees, and is used for lacquerware including tableware, containers, furniture and artistic objects. Oriental lacquer has a low environmental impact and is known as a "green coating", because it is derived from a renewable resource and does not produce as many volatile organic compounds as petrochemical coatings [1,2]. Lacquer films have satiny texture, excellent character, and high durability, imparting long-lasting, elegant beauty to lacquerware. The composition of oriental lacquer is influenced by its cultivar, habitat, age, and harvest season [3]. Oriental lacquer is composed of $60 \%-65 \%$ urushiols, with the rest being $20 \%-25 \%$ water, $5 \%-7 \%$ plant gum, $2 \%-5 \%$ nitrogenous compounds, and approximately $1 \%$ laccase [4]. Urushiols contain 1,2,3-tri-o- or 1,3-di-o-substituted catechol and isomers containing double bonds or small amounts of saturated alkyl groups [5]. The catechol derivatives can be further identified by time-of-flight secondary ion mass spectrometry. For example, a series of urushiol and laccol repeat units were identified in Rhus vernicifera from Korea and China and in Rhus succedanea from Vietnam [6]. The gum is a water-soluble pentose similar to Arabic gum that functions as an emulsifier to encapsulate and disperse water molecules in the urushiols [5]. Nitrogenous compounds are identified as glycoproteins that are insoluble in acetone or water. Laccase is a copper-containing polyphenol oxidase that enables the oxidative polymerization 
of urushiols [7]. To refine the oriental lacquer for multipurpose utilization, its water content must be reduced and its molecular weight increased. After the refining process, oriental lacquer becomes a refined lacquer (RL) with a black color, transparency, gloss, oligomer, and polymer content that is higher than in its initial state. With a curing time shorter than that of oriental lacquer, RL is often used for the surface decoration of precious wares, as mentioned above [8].

In a previous report [9], the organic constituents of oriental lacquer formulations were evaluated. The five most important vegetable oils associated with the production of oriental lacquer are perilla oil, tung oil, sesame oil, tallow tree oil, and linseed oil. These vegetable oils are blended with oriental lacquer to obtained desirable properties such as low viscosity, high gloss and transparency of the resulting film, softer and slower cure, and for reasons of economy. Vegetable oils are important natural coatings that are classified as a drying oils, semidrying oils, or nondrying oils, based on their iodine value. If the iodine value of an oil is $>130$, it is considered to be a drying oil (e.g., linseed oil (LO) and tung oil (TO)) [10]. The large amount of unsaturated fatty acids in drying oil readily reacts with atmospheric oxygen, leading to autoxidation and polymerization, thereby crosslinking the unsaturated fatty acids and hardening the oil into film. One of the unsaturated fatty acids in TO's triglyceride structure is eleostearic acid, which contains three conjugated double bonds. This characteristic makes it susceptible to oxidative polymerization, as the conjugated double bonds form peroxides with oxygen that react with another unsaturated fatty acid via addition polymerization to form a crosslinked network [11]. Thus, TO dries the quickest and is commonly used as a raw material in coatings [12,13]. The iodine value of LO is 170-204, slightly higher than that of TO [10]. LO is composed of a number of fatty acids: $53 \%$ linolenic acid, $15 \%$ linoleic acid, $18 \%$ oleic acid, $6 \%$ hexadecanoic acid, and $6 \%$ stearic acid. Unlike in TO, the methylene next to an unsaturated double bond in LO is activated by dehydrogenation during oxidative polymerization. The double bonds are converted from cis to the more thermodynamically stable trans form and produce hydroperoxides via the reaction of trans free radicals with oxygen in an autoxidation process. The hydroperoxides decompose into free radicals, which trigger propagation reactions. In the termination step, the fatty acids are linked by $\mathrm{C}-\mathrm{C}, \mathrm{C}-\mathrm{O}-\mathrm{C}$, or $\mathrm{C}-\mathrm{O}-\mathrm{O}-\mathrm{C}$ bonds to form an insoluble network-like coating $[14,15]$. Dehydrated castor oil (DCO) is produced through the dehydration of raw castor oil, in which ricinoleic acid forms C-9, 11-conjugated and C-9, 12-nonconjugated linoleic acids, whose drying properties are between those of TO and LO [16].

During the curing of the RL, urushiols are transformed into less-antioxidative quinones through the catalytic polymerization of laccase. The unsaturated double bonds on the side chains of urushiols undergo autoxidation and polymerization to form four main types of urushiols dimer: Carbon-carbon coupling products of urushiol, dibenzofurans, nucleus to side-chain carbon-carbon and carbon-oxygen coupled compounds, and side-chain hydroxylated compounds [7]. Finally, a highly crosslinked network structure is obtained, which imparts excellent hardness, wear resistance, and durability to the RL films but also makes them hard, brittle, and less ductile. Additionally, to obtain a high-gloss $\mathrm{RL}$, the mixing blade must be much closer to the wall of the container during the refining process. The higher frictional heat reduces the activity of laccase and results in an RL that is slow- or nondrying. Therefore, the most practical method to obtain high-gloss RL is to blend drying oils during the refining process.

When drying oil is added to refined lacquer, oxidative polymerization occurs and the unsaturated fatty acids of the drying oil undergo addition polymerization with the side chains of urushiols. This facilitates the curing of the RL, which endows the coating film with flexibility and transparency, lightens the color, provides a glossier appearance, and makes color blending easier [17]. Therefore, it is of interest to find the drying oil (and amount of oil) that is best at reducing cost and improving properties of lacquer and lacquer films. In this study we blended RL with TO, LO, and DCO and examined the effects of the type and quantity of drying oil on the properties of oil-modified refined lacquer (OMRL). 


\section{Materials and Methods}

\subsection{Materials}

The oriental lacquer, harvested from the cultivar Rhus succedanea, was purchased from the Long-Nan Museum of Natural Lacquer Ware in Nantou, Taiwan. The sample was milky-yellow in color and was analyzed in our laboratory. The following data were obtained: (1) The lacquer was composed of $54.1 \% \pm 0.3 \%$ urushiols, $7.2 \% \pm 0.4 \%$ plant gum, $4.4 \% \pm 0.7 \%$ nitrogenous compounds, and $34.3 \% \pm 0.1 \%$ water (the separation of the oriental lacquer was performed with as described in a previous study [18] and the CNS 2810 Standard [19]); (2) the viscosity was 1494 cps according to a Brookfield viscometer DV-E (Brookfield Engineering, Middleboro, MA, USA); and (3) the weight-average molecular weight $\left(M_{\mathrm{W}}\right)$ was 1072 , and the number-average molecular weight $\left(M_{n}\right)$ was 682, according to GPC analysis. Acetone was purchased from Merck Co., Taipei, Taiwan. The iodine value (IV) of the raw TO was 151, as prescribed by the CNS 3646 Standard [20]. The IV of the LO was 180, and the IV of the DCO was 146. All of these materials were commercially available. Cryptomeria japonica boards (with a moisture content of 10.7\%), glass sheets, an S-16 wear-resistant steel plate, tin-coated iron sheets, and Teflon sheets were all prepared as specified by the CNS 9007 Standard [21] and were used as experimental substrates.

\subsection{Preparation of Refined Lacquer and Oil-Modified Refined Lacquer}

The oriental lacquer (400 g) was placed in a glass container and stirred at $60 \mathrm{rpm}$ while being heated to $40^{\circ} \mathrm{C}$, with the mixing blades $5 \mathrm{~mm}$ from the bottom of the container, until the water content was reduced to $3.5 \%$. Refining took around $12 \mathrm{~h}$ to complete. During the preparation of the RL, different quantities of TO, LO, and DCO were added when the water content of the RL reached $10 \%$ (around $9.5 \mathrm{~h}$ ), to achieve weight ratios of $0 / 100,10 / 100$, and 20/100 between the drying oil and the RL. Refining was continued until the water content was reduced to 3.5\%. Viscosity was measured at $26^{\circ} \mathrm{C}$ using a Brookfield Viscometer DV-E (Brookfield Engineering, Middleboro, MA, USA).

\subsection{Determination of Coating Properties}

Drying time was measured with a Beck Koller Drying Time Recorder (BYK-Gardner, Geretsried, Germany). The OMRL was coated on long glass sheets to form wet films with a thickness of $76 \mu \mathrm{m}$. The specimens were placed in the recorder and measured at a constant temperature of $25^{\circ} \mathrm{C}$ and a constant relative humidity $(\mathrm{RH})$ of of $80 \%$. The drying process was then categorized into a dust-free dry (DF), which corresponded to the trace of $\mathrm{O} \rightarrow \mathrm{A}$ as shown in Figure 1, touch-free dry $(\mathrm{TF}, \mathrm{O} \rightarrow \mathrm{B})$ and hardened dry $(\mathrm{HD}, \mathrm{O} \rightarrow \mathrm{C})[22]$.
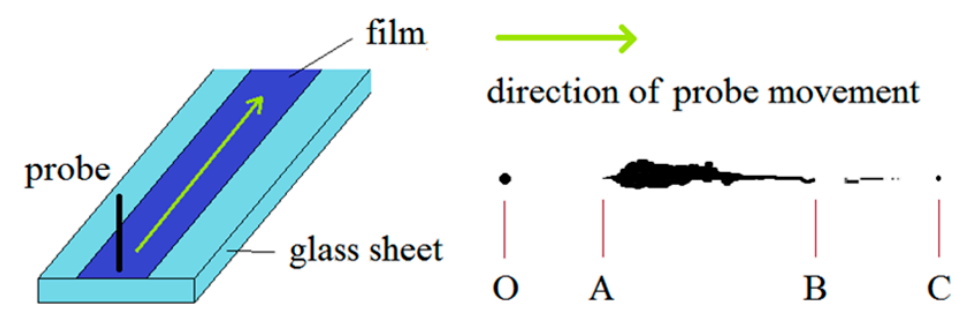

Figure 1. The drying time test method and trace of a coating during the drying process. $\mathrm{O} \rightarrow \mathrm{A}$ : The film possessed good fluidity. The trace disappeared after the probe. $\mathrm{A} \rightarrow \mathrm{B}$ : The surface of the film had dried, but the base had not. The film surface adhered to the probe and left behind thick traces. $B \rightarrow C$ : The film had dried further. The probe left only fine marks after crossing the film. C: The film had completely dried. The probe did not leave any trace. 


\subsection{Determination of the Film Properties}

The selected substrates were coated using a universal applicator with a wet film thickness of $100 \mu \mathrm{m}$, and were placed in a constant temperature and humidity chamber at $25^{\circ} \mathrm{C}$ and $80 \% \mathrm{RH}$ for 1 day, followed by drying in an air-conditioned environment at $26^{\circ} \mathrm{C}$ and $60 \% \mathrm{RH}$ for three weeks. The tests were carried out after this drying process. Hardness was measured using a König/Persoz Pendulum Hardness Tester from Braive Instruments (Liège, Belgium), according to the ISO 1522 [23]. To conduct the mass retention measurements, films were separated from the substrates, were placed as self-supporting films in extraction thimbles, and were heated in a Soxhlet extractor (Dogger Co., New Taipei City, Taiwan) with refluxing acetone for four cycles (fill/siphon) $/ \mathrm{h}$. After $6 \mathrm{~h}$, the films were taken out and dried to calculate their mass retention. The glass transition temperature $\left(T_{\mathrm{g}}\right)$ of the films was measured using dynamic mechanical analysis (DMA) under tension mode using a PerkinElmer DMA 8000 (PerkinElmer, Waltham, MA, USA) at $1 \mathrm{~Hz}$, with the temperature increasing from 30 to $170{ }^{\circ} \mathrm{C}$ at $5{ }^{\circ} \mathrm{C} \mathrm{min}{ }^{-1}$. Bending resistance was determined using a bending tester (Ueshima Seisakusho Co., Ltd., Tokyo, Japan) with steel bars possessing diameters of 2, 3, 4, 6, 8, and $10 \mathrm{~mm}$. The films were coated on tin-coated iron sheets $(0.02 \mathrm{~cm} \times 5 \mathrm{~cm} \times 15 \mathrm{~cm})$, and the test was performed according to JIS-K-5400 [24]. The bars' diameters of film rupture were recorded: A smaller diameter indicated a higher bending resistance.

The tensile strength and elongation at break were performed using films conforming to ASTM D-638 Standard [25]. Films were subsequently tested using a Shimadzu EZ Test Series Tensile Tester (Shimadzu, Kyoto, Japan) at a speed of $5 \mathrm{~mm} \mathrm{~min}^{-1}$. Seven samples were tested for each film, and the values were averaged. Impact resistance was measured using an impact tester (IM-601, IDM Instruments Pty Ltd., Hallam, Victoria, Australia). The impact needle had a diameter of $2.54 \mathrm{~cm}$, and the falling weight was $300 \mathrm{~g}$. Adhesion was tested using the crosscut method outlined in CNS $10756 \mathrm{~K} 6800$ [26]. The adhesion of the film varied between 10, 8, 6, 4, 2, and 0 . Abrasion resistance was performed using a Taber Abrasion Tester with a CS-10 abrading wheel using a load of $500 \mathrm{~g}$. The mass losses of the films after 1000 abrasion cycles were recorded. Gloss was measured using a Dr. Lange $60^{\circ}$ Reflectometer (Dr. Bruno Lange $\mathrm{GmbH}$, Berlin, Germany) in the direction of the wood texture. Color fading of films was tested by exposing them to a fade meter (SUGA Test Instruments Co., Ltd., Tokyo, Japan) at $32 \pm 4{ }^{\circ} \mathrm{C}$, using an H400-F mercury lamp (SUGA Test Instruments Co., Ltd., Tokyo, Japan) as the light source. The color of the films before and after exposure to light was measured using a Minolta Spectrophotometer CM-3600d (Konica Minolta, Osaka, Japan) with an $8 \mathrm{~mm}$ target mask and a D65 light source. The sensor was aligned at $10^{\circ}$ to the surface of each specimen. The color difference $\left(\Delta E^{*}\right)$ was calculated using the $\operatorname{CIE} L^{*} a^{*} b^{*}$ color space.

\section{Results and Discussion}

\subsection{Properties of the Oil-Modified Refined Lacquer Coatings}

During the refining process of the oriental lacquer, the timing of the addition of drying oil to lacquer was very important. As an example for TO, when the water content of the oriental lacquer reached $30 \%, 20 \%$, and $10 \%$, TO was added to the given batch to achieve an oil/oriental lacquer weight ratio of 20/100. Then, refining continued until the water content was reduced to $3.5 \%$. This process led to the TO-modified RL. The time for hardened drying (HD) was measured. Results showed that when the water content of the oriental lacquer was at $30 \%, 20 \%$, and $10 \%$, the HD of the RL was 13.5, 11.0, and $7.0 \mathrm{~h}$, respectively. This finding indicated that the suitable point for adding the drying oil to lacquer during refining occurred when its water content reached $10 \%$.

The viscosity and drying time of the RL with different types of drying oil and weight ratios are listed in Table 1. The RL had a viscosity of $2927 \mathrm{cps}$, whereas the viscosities of all three drying oils were lower. LO (L100) had the lowest viscosity at only 55 cps. More than $70 \%$ of the fatty acids of TO (T100) is eleostearic acid, which contains three highly reactive conjugated double bonds for easy oxidative addition in an aerobic environment, which in turn increases the molecular weight of $\mathrm{TO}$ and gives it a 
viscosity of 257 cps. The ricinoleic acid in raw castor oil dehydrates at high temperatures to form two types of linoleic acids, one with conjugated double bonds and the other with nonconjugated double bonds. At 174 cps, the viscosity of DCO (D100) was slightly lower than that of TO. After the blending and refining process of the oriental lacquer with different types of drying oil, T10 and D10 (with an oil/oriental lacquer weight ratio of 10/100) both had viscosities higher than RL, and the viscosity of T10 was also greater than that of D10, indicating that drying oils acted as more than diluents for RL. In particular, the conjugated double bonds in the unsaturated fatty acids of TO and DCO could undergo autooxidation or with the unsaturated side chains of urushiols as the oriental lacquer was refined with these drying oils. This led to an overall increase in molecular weight and viscosity of the OMRL. On the other hand, in L10, although the fatty acids of LO contained $40 \%$ linolenic acid and a large number of double bonds, all of the double bonds were nonconjugated and did not undergo significant oxidative addition during the refining process. Thus, the OMRL that was obtained did not have a high viscosity. When the ratio of the drying oils reached $20 / 100$, oxidative addition still had the effects highlighted above. However, once an excess of low-viscosity drying oil was introduced to the process, it began to dilute the RL and ultimately reduced the OMRL viscosity. The addition of the drying oil, which enhanced the workability and utilization of OMRL, made it possible to use ordinary coating brushes instead of those made from human hair for the application of RL.

Table 1. Viscosity and drying time of refined lacquer with different types of drying oil and weight ratios. DF: Dust-free dry; TF: Touch-free dry; HD: Hardened dry.

\begin{tabular}{ccccccc}
\hline \multirow{2}{*}{$\begin{array}{c}\text { Sample } \\
\text { Code }\end{array}$} & $\begin{array}{c}\text { Type of } \\
\text { Drying Oil }\end{array}$ & $\begin{array}{c}\text { Oil/Oriental } \\
\text { Lacquer (by wt } \mathbf{\%})\end{array}$ & $\begin{array}{c}\text { Viscosity } \\
\left(\mathbf{c p s}, \mathbf{2 6} \mathbf{~}^{\circ} \mathbf{C}\right)\end{array}$ & \multicolumn{2}{c}{ Drying Time (h) } \\
\cline { 5 - 7 } & - & $0 / 100$ & 2927 & 3.5 & 4.5 & 7.0 \\
\hline RL & & $10 / 100$ & 3684 & 3.0 & 4.0 & 7.0 \\
T10 & Tung oil & $20 / 100$ & 2670 & 3.5 & 4.0 & 7.0 \\
T20 & $100 / 0$ & 257 & - & - & 96.0 \\
T100 & & $10 / 100$ & 3216 & 3.0 & 4.0 & 6.5 \\
\hline D10 & Dehydrated & $20 / 100$ & 2204 & 3.0 & 3.5 & 5.0 \\
D20 & castor oil & $100 / 0$ & 174 & - & - & 120.0 \\
D100 & & $10 / 100$ & 2678 & 3.0 & 4.0 & 8.0 \\
\hline L10 & & $20 / 100$ & 1747 & 3.0 & 3.5 & 5.5 \\
L20 & Linseed oil & $100 / 0$ & 55 & - & - & 192.0 \\
L100 & & & & & &
\end{tabular}

The drying times of the coated specimens at $25{ }^{\circ} \mathrm{C}$ and $80 \% \mathrm{RH}$ are also given in Table 1 . As described in previous research $[4,8,16]$, in the initial drying stages of traditional oriental lacquer, laccase reacts with oxygen and promotes free radical polymerization to produce phenoxy radicals from urushiols, which are also known as urushiol semiquinone radicals. This drying stage corresponds to DF in the curing test. These radicals are then disproportionated to produce urushiol quinones: This is the TF drying stage. When urushiols are polymerized into urushiol quinones and lose their antioxidant activity, their side chains oxidize and polymerize to produce densely crosslinked film in the HD drying stage. The DF and HD drying times of RL measured in this study were 3.5 and $7 \mathrm{~h}$, respectively, consistent with previously reported results. As the oxidative polymerization and complete hardening of drying oils can take weeks or even months, none of the drying oils used here reached the HD stage within one day. The TO with conjugated double bonds took at least $96 \mathrm{~h}$ to harden. The oxidative addition and polymerization of drying oils also require atmospheric oxygen: However, because oxygen diffused into the interior of the wet film, an oxygen concentration gradient was formed between the film surface and the interior, leading to different drying rates throughout the film. When the surface dried too quickly, it toughened and blocked oxygen penetration into the interior, resulting in incomplete drying inside the film. OMRL containing drying oils is also potentially subject to such uneven drying. 
In DCO-modified RLs, the TF and HD time was shortened as more DCO was added and became shorter than those of the RL. This is because the low viscosity of the oil-modified RL allows oxygen to easily permeate into the coating, promoting the laccase-catalyzed polymerization and reducing the TF time. The abundant conjugated double bonds also participate in the oxidative polymerization of urushiol side chains, thus decreasing the time it takes to reach the HD stage.

The DF and TF times of TO-modified refined lacquers were shorter than RL, but the HD time was the same $(7.0 \mathrm{~h})$. This was due to the three highly reactive conjugated double bonds on the eleostearic acid of TO, which increased the viscosity of the coating material during the early drying, hardening the surface of the film and blocking oxygen penetration. Thus, the ability of laccase to catalyze oxidation polymerization was reduced, which was not beneficial to the drying of the RL.

For the LO-modified refined lacquers, the DF and TF times of L10 and L20 were shorter than those of RL, but the HD time varied with the amount of LO added. The HD time of L20 was only $5.5 \mathrm{~h}$, whereas that of L10 was $8.0 \mathrm{~h}$. This was due to the high content of linolenic acid, which was characterized by nonconjugated double bonds, in the fatty acids of $\mathrm{LO}$ and a reactivity that fell between that of TO and DCO. As a result, the HD time of the RL was shortened only when the proportion of drying oil/oriental lacquer reached 20/100.

\subsection{Properties of OMRL Films}

After the RLs blended with the three respective drying oils hardened into films at $25{ }^{\circ} \mathrm{C}$ and $80 \% \mathrm{RH}$ in a constant temperature and humidity chamber, they were placed in an air-conditioned environment at $26{ }^{\circ} \mathrm{C}$ and $60 \% \mathrm{RH}$ for 3 weeks. The film properties, including the hardness, mass retention, $T_{\mathrm{g}}$, bending resistance, tensile strength, and elongation at break, were then determined (as shown in Table 2).

Table 2. The hardness, mass retention, $T_{\mathrm{g}}$, and bending resistance of oil-modified refined lacquer (OMRL) films.

\begin{tabular}{|c|c|c|c|c|c|c|}
\hline $\begin{array}{l}\text { Sample } \\
\text { Code }\end{array}$ & $\begin{array}{l}\text { Hardness } \\
\text { (König, sec) }\end{array}$ & $\begin{array}{c}\text { Mass } \\
\text { Retention }^{1}(\%)\end{array}$ & $T_{\mathrm{g}}\left({ }^{\circ} \mathrm{C}\right)$ & $\begin{array}{c}\text { Bending } \\
\text { Resistance }(\mathrm{mm})\end{array}$ & $\begin{array}{c}\text { Tensile } \\
\text { Strength (MPa) }\end{array}$ & $\begin{array}{c}\text { Elongation } \\
\text { at Break (\%) }\end{array}$ \\
\hline RL & $104 \pm 1$ & $91.6 \pm 0.5$ & 80.2 & $>10$ & $27.6 \pm 0.8$ & $12.0 \pm 0.6$ \\
\hline $\mathrm{T} 10$ & $81 \pm 2$ & $86.4 \pm 0.6$ & 55.0 & 8 & $20.7 \pm 0.7$ & $19.0 \pm 0.7$ \\
\hline $\mathrm{T} 20$ & $80 \pm 1$ & $87.1 \pm 0.7$ & 44.5 & 4 & $9.1 \pm 0.6$ & $30.8 \pm 1.6$ \\
\hline $\mathrm{T} 100$ & $70 \pm 5$ & - & $10.4^{2}$ & 3 & - & - \\
\hline L10 & $61 \pm 2$ & $86.0 \pm 0.5$ & 59.9 & 8 & $15.2 \pm 1.2$ & $21.6 \pm 0.7$ \\
\hline L20 & $33 \pm 1$ & $80.6 \pm 0.7$ & 27.8 & 4 & $8.3 \pm 0.4$ & $34.2 \pm 2.9$ \\
\hline L100 & $29 \pm 2$ & - & $-12.5^{2}$ & $>2$ & - & - \\
\hline D10 & $83 \pm 1$ & $87.2 \pm 0.4$ & 66.6 & 6 & $13.0 \pm 0.7$ & $19.0 \pm 1.0$ \\
\hline D20 & $52 \pm 2$ & $81.4 \pm 0.8$ & 33.0 & 4 & $7.0 \pm 0.6$ & $28.4 \pm 2.9$ \\
\hline D100 & $63 \pm 2$ & - & $-14.0^{2}$ & $>2$ & - & - \\
\hline
\end{tabular}

The RL film had a hardness of $104 \mathrm{~s}$, whereas the other OMRL films all exhibited lower hardness. The values for T10 and T20, the TO-modified RLs, were 81 and $80 \mathrm{~s}$, respectively; D10 and D20, the DCO-modified RLs, had hardness values of 83 and $52 \mathrm{~s}$, respectively; and L10 and L20, the LO-modified refined lacquers, had hardness values of 61 and $33 \mathrm{~s}$. Previous literature [27] has used a multianalytical approach and has reported that the catechol acts as an antioxidant, inhibiting the oxidation reactions of linseed oil, and is accompanied by an increase in the occurrence of propagation and termination reactions leading to crosslinking. However, in our study, the oils were added when the water content of the RL reached $10 \%$. At this stage, over $50 \%$ of catechol monomers had been transformed into oligomers and polymers [4], which weakened the antioxidant of RL. As is evident from our results, the highly reactive eleostearic acid in the TO-modified RLs readily formed cyclic peroxide with oxygen and decomposed into either oxygen or peroxy radicals, initiating polymerization and the rapid drying of the RL into a film. When TO was blended with the oriental 
lacquer, the fast-oxidative polymerization inhibited the catalytic polymerization by laccase, but still enabled the formation of a highly crosslinked film or a film with a tough surface [9]. For linolenic acid in LO, which contains nonconjugated double bonds, the oxidative polymerization required dehydrogenation by methylene, after which it reacted with oxygen to form hydroperoxide and decomposed into either oxygen or peroxy radicals, initiating the crosslinking reaction. Therefore, the drying time of LO-modified RLs was longer [14]. The oxidative polymerization of LO also competed with the catalyzed polymerization by laccase, lowering the crosslink density of the dried film and giving rise to a softer film. The DCO contained both conjugated and nonconjugated double bonds, and thus the film hardness of the DCO-modified RLs was between that of the TO and the LO-modified RLs.

The mass retention for each RL composition is listed in Table 2. Except for the pure drying oils (T100, L100, and D100), from which isolated films could not be obtained. The highest mass retention was seen for RL (91.6\%), whereas all the other OMRLs containing $10 \%$ oils showed similar and lower values. Although the mass retention of pure drying oils could not be measured, the crosslink density of the films of LO and DCO-modified RLs were found to decrease as the LO or DCO content increased. This indicated the possible slowing effect that the antioxidant activity of urushiols had on the oxidative polymerization of drying oils, or the competition between the crosslinking that occurred during the oxidative polymerization of the drying oils and the catalyzed polymerization by laccase, which lowered the crosslink density in the film. However, when the TO content was increased from $10 \%$ to $20 \%$, a small increase in mass retention (from $86.4 \%$ to $87.1 \%$ ) was observed in the TO-modified RLs because $\mathrm{TO}$ is composed of unsaturated fatty acids with highly reactive conjugated double bonds that are unaffected by the antioxidant activity of urushiols. Although it inhibited the catalyzed polymerization by laccase, the oxidative polymerization of TO still formed crosslinked structures as TO underwent rapid oxidative polymerization with urushiol side chains, giving the film its high mass retention. Due to the abundance of conjugated double bonds in the fatty acids of DCO, the mass retention in films formed by DCO-modified RLs was slightly higher than in their LO counterparts.

Figure 2 shows the DMA results of the films and the $T_{\mathrm{g}}$ values of the films as given by the peaks of the $\tan \delta$ plots shown in Table 2. As intact films of the three pure drying oils could not be obtained, the standard method of film chips covered in aluminum was used to measure the $T_{\mathrm{g}}$ of the films. The RL film had the highest $T_{\mathrm{g}}$ at $80.2{ }^{\circ} \mathrm{C}$, indicating a high degree of crosslinking, as is also reflected in the mass retention results. The $T_{\mathrm{g}}$ of the various OMRLs decreased as the drying oil proportion increased, with the highest $T_{\mathrm{g}}$ recorded in D10 at $66.6^{\circ} \mathrm{C}$, whereas T10 and L10 had similar $T_{\mathrm{g}}$ values of $55.0^{\circ} \mathrm{C}$ and $59.9^{\circ} \mathrm{C}$, respectively. These results were also consistent with the mass retention. In addition, the film of TO-OMRL showed narrower $\tan \delta$ peaks than the LO-OMRL and DCO-OMRL films did, which indicates that the network structure of the TO-OMRL films was more homogeneous than the other ones.
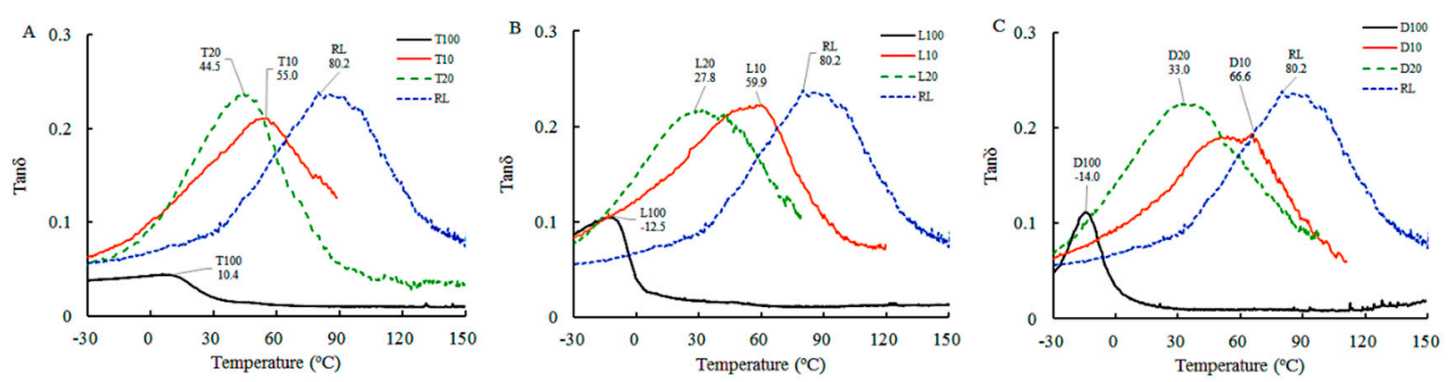

Figure 2. Tan $\delta$ of OMRL films: (A) Tung oil (TO)-modified refined lacquer; (B) linseed oil (LO)-modified refined lacquer; and $(\mathrm{C})$ dehydrated castor oil (DCO)-modified refined lacquer.

The results above show that OMRL, composed of long chain fatty acids, had lower rigidity than the RL. The crosslinking reaction was still possible for the films of TO-modified RLs as the highly reactive eleostearic acid in TO could still undergo oxidative polymerization despite the antioxidant activity of urushiols. Therefore, the mass retention of the films increased even as the quantity of TO increased 
from $10 \%$ to $20 \%$, and the decrease in $T_{\mathrm{g}}$ was smaller (from 55.0 to $44.5^{\circ} \mathrm{C}$ ). The iodine value of $\mathrm{LO}$ was higher than that of DCO, which indicates that the crosslinking density in films of LO-modified RLs should be higher than that of their DCO counterparts, whose fatty acids were completely oxidized and polymerized. However, the mass retention and DMA tests showed opposite results, which suggests that the laccase-catalyzed polymerization of oriental lacquer competed effectively with the oxidative polymerization of the drying oils, resulting in incomplete oxidative polymerization. On the other hand, the DCO consisted of fatty acids with highly reactive double bonds, giving the RL films a higher mass retention and $T_{\mathrm{g}}$. The high hardness, mass retention, and $T_{\mathrm{g}}$ values exhibited by the films of DCO-modified RLs also indicate the presence of both conjugated and nonconjugated double bonds in the fatty acids of DCO, which formed highly crosslinked films despite the possibility of laccase-catalyzed polymerization.

The bending resistance test results showed that the film formed by the RL was hard and brittle and was broken using a $10 \mathrm{~mm}$-diameter steel bar. Films of pure drying oils all demonstrated good bending resistance during a 2-3 mm-diameter steel shaft test. The addition of $\mathrm{TO}, \mathrm{LO}$, and DCO greatly improved the bending resistance of the OMRL films. A higher bending resistance was observed as more drying oils were added, as seen for D10 and D20, which were tested using 6 and 4 mm-diameter steel bars, respectively. This finding shows the enhanced flexibility of OMRL films as compared to traditional RL films.

The tensile strength and elongation at break for the films are shown in Figure 3. The T100, L100, and D100 films were so low in strength that intact films could not be isolated. The tensile strength of the RL film was around 27.6 MPa. The tensile strengths of the OMRL films all decreased with an increase in the proportion of drying oil, as drying oils reduced the crosslinking density of the films. Among the OMRLs, films of TO-modified RLs showed the highest tensile strength of $20.7 \mathrm{MPa}$ (T10), whereas the films of LO and DCO-modified RLs had similar tensile strengths of approximately 13.0 (D10) and 15.2 MPa (L10). With the addition of $10 \%$ or $20 \%$ drying oil, the DCO-modified RLs had the lowest tensile strengths. Although these films had the highest crosslinking density, they had poor homogeneity as both conjugated and nonconjugated fatty acids participated in the oxidative polymerization as the films dried, in addition to the laccase-catalyzed polymerization. This suggestion is supported by the observation that D10 showed the broadest peak in the DMA test results (Figure 2c).

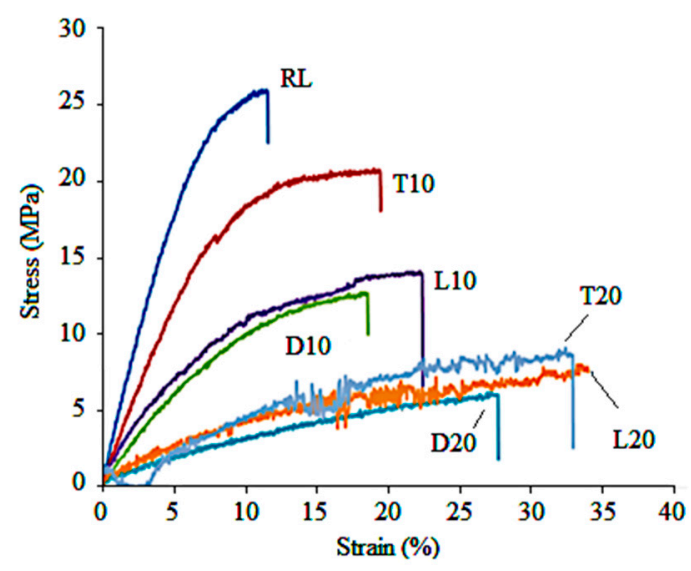

Figure 3. Stress-strain curves of OMRL films.

The elongation at break for RL was only about $12 \%$, but it increased for the OMRL films as more drying oils were added. The best results were obtained for LO-modified RLs, which had an elongation at break of $34.2 \%$ for $\mathrm{L} 20$. The unsaturated fatty acids of $\mathrm{LO}$ contain nonconjugated double bonds and show low reactivity in oxidation polymerization. Thus, films of LO-modified RLs are not exhibit dense crosslinking and possess soft and flexible as a result. 
The impact resistance, adhesion, abrasion resistance, and gloss of OMRL films are listed in Table 3. Because pure drying oils penetrated into the wooden test boards after application, they could not be tested for impact resistance. The RL film was hard and brittle, but it withstood the impact of a fall from $5 \mathrm{~cm}$. The OMRL films all showed reasonably high impact resistance of about 10-20 cm, with the highest exhibited by T20, L20, and D20. Both RL and pure drying oils (T100, L100, and D100) showed an excellent adhesion of grade 10, but the adhesion of OMRL was low and decreased with an increasing content of drying oil. Among the various OMRLs, the adhesion of LO and DCO-modified RL dropped most significantly. The oxidative polymerization of drying oils depended on the penetration of atmospheric oxygen into the wet film, but oxygen permeation was impeded with increasing film thickness and coating material viscosity, resulting in an oxygen concentration gradient in the wet film. The oxygen concentration at the film's surface was higher, which led to oxidative polymerizations rates that varied between the surface and the bottom of the film. This effect was more substantial when the fatty acids in the drying oils were not very reactive.

Table 3. The impact resistance, adhesion, abrasion resistance, and gloss of OMRL films.

\begin{tabular}{ccccc}
\hline $\begin{array}{c}\text { Sample } \\
\text { Code }\end{array}$ & $\begin{array}{c}\text { Impact Resistance } \\
(\mathbf{c m})\end{array}$ & $\begin{array}{c}\text { Adhesion } \\
\text { (grade) }\end{array}$ & $\begin{array}{c}\text { Abrasion Resistance } \\
\text { (mg/1000 cycles) }\end{array}$ & $\mathbf{6 0}^{\circ}$ Gloss \\
\hline RL & 10 & 10 & $13.2 \pm 0.7$ & $26 \pm 2$ \\
\hline T10 & 15 & 8 & $14.1 \pm 1.8$ & $35 \pm 1$ \\
T20 & 20 & 8 & $18.3 \pm 2.4$ & $52 \pm 1$ \\
T100 & - & 10 & - & $2 \pm 0$ \\
\hline L10 & 10 & 8 & $11.5 \pm 2.6$ & $43 \pm 1$ \\
L20 & 20 & 4 & $27.4 \pm 2.7$ & $82 \pm 3$ \\
L100 & - & 10 & - & $6 \pm 2$ \\
\hline D10 & 10 & 10 & $13.7 \pm 0.8$ & $33 \pm 1$ \\
D20 & 20 & 6 & $32.2 \pm 3.4$ & $54 \pm 2$ \\
D100 & - & 10 & - & $3 \pm 1$ \\
\hline
\end{tabular}

The abrasion resistance of OMRL films is also shown in Table 3. The weight loss due to abrasion for an RL film after 1000 test cycles was $13.2 \mathrm{mg}$. The weight loss of OMRL films increased with increasing content of drying oil. With the exception of the L10 film (a weight loss of $11.5 \mathrm{mg}$ ), the other OMRL films all lost more weight (approximately 13.7-32.2 mg) than the RL. D20 film had the highest weight after the abrasion test at $32.2 \mathrm{mg}$, whereas that of the D10 film was closest to RL at $13.7 \mathrm{mg}$. The results of the abrasion resistance test were consistent with the tensile stress-strain curves of Figure 3 [28], which show the smallest area-under-curve for the D20 film. The $60^{\circ}$ gloss of RL film had a value of $26 \%$, whereas OMRL films all showed greatly improved gloss, particularly L20, which had a gloss value of $82 \%$. The films of TO and DCO-modified RLs showed little difference in this respect, and all had high gloss values, such as 52\% and 54\% for T20 and D20, respectively. Drying oils reduced the viscosity of the RLs, facilitating flattening of the film and the release of air bubbles, which made the film surface smoother after drying. The OMRL films with drying oils had a high gloss and were lustrous in appearance, and hence are well suited for their special end-uses.

According to a previous study, aging of the RL films is detrimental to their properties. For example, Lu et al. [29] reported that a chemical reaction occurred quickly $(48 \mathrm{~h})$ on the surface of the oriental lacquer film after UV irradiation, and an $\mathrm{Fe}^{2+}$ ion-containing lacquer film deteriorated more quickly than a kurome lacquer film. Another study [30] showed that aging (within 1000 days) increased strength and reduced the ductility of the oriental lacquer films. A further study [31] examined the effects of aging and moisture on the dynamic viscoelastic properties of oriental lacquer films. This study showed that the film's $T_{\mathrm{g}}$ shifted to higher temperatures, the maximum loss tangent $(\tan \delta)$ decreased, and the storage modulus increased after aging over 1000 days at room temperature. We focused on changes in appearance of films during the UV irradiation. The lightfastness values of the OMRL films 
before and after the color fading test are given in Figure 4. The color difference $\left(\Delta E^{*}\right)$ of RL and OMRL films increased with prolonged exposure under ultraviolet light irradiation, accounting for the color changes of the films. The $\Delta E^{*}$ values of RL during the first $72 \mathrm{~h}$ were lower than those of the pure drying oils (T100, L100, and D100), but steadily rose after $72 \mathrm{~h}$ of irradiation. Conversely, the drying oils did not show any increase. This was because RL contains a large number of aromatic rings that are easily converted into quinones and undergo photodegradation, thus increasing $\Delta E^{*}$. The $\Delta E^{*}$ of drying oils did not increase appreciably but still had values of 11-17, with the highest observed in TO and the lowest in DCO. This was related to the unreacted or newly formed conjugated double bonds in the films, as these conjugated double bonds absorb light and are common chromophores. The OMRL films with $10 \%$ drying oil added showed $\Delta E^{*}$ variations similar to the pure drying oils, with $\Delta E^{*}$ values in the following order: TO-modified RL > LO-modified RL > DCO-modified RL. When the proportion of drying oil increased to $20 \%$, the $\Delta E^{*}$ of the TO-modified RLs decreased significantly. The order of $\Delta E^{*}$ became LO-modified RL $>$ DCO-modified RL $>$ TO-modified RL. As TO was blended with oriental lacquer, rapid oxidative polymerization inhibited and dominated the laccase-catalyzed polymerization, forming highly crosslinked films. Fewer conjugated double bonds were left in the film, reducing $\Delta E^{*}$. Generally speaking, the $\Delta E^{*}$ values of OMRLs were higher than RL, as the colors of the OMRL films were lighter, resulting in greater color changes. In the lightfastness test, the $\Delta E^{*}$ values of OMRL films were found to stabilize at $96 \mathrm{~h}$, whereas those of RL continued to rise. Lightfastness tests of longer duration or with a higher irradiation intensity are needed to draw firmer conclusions about the lightfastness of oil modified lacquer films.

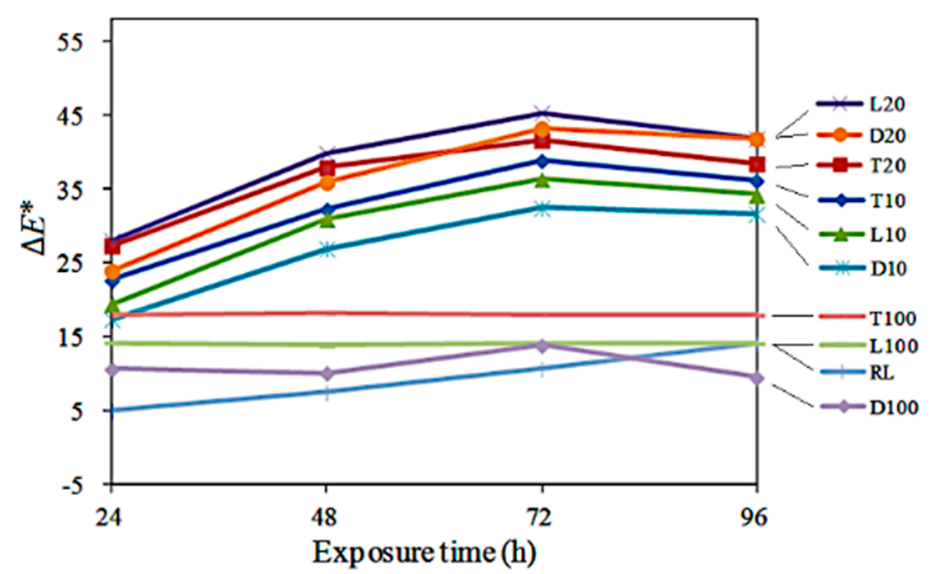

Figure 4. Time-dependent color difference $\left(\Delta E^{*}\right)$ of OMRL films under UV light irradiation.

According to our experimental results, the OMRL containing 10\% tung oil had better film flexibility and gloss than the RL films and possessed superior hardness, which are desirable properties for finishing of wooden furniture. Even if the OMRL contained $20 \%$ linseed oil it had low film tensile strength of film, but it had the highest gloss, lowest viscosity and fast curing time, which are properties that are desirable for artistic applications, for example, colored paintings.

\section{Conclusions}

Different OMRLs were prepared by adding TO, LO, and DCO into oriental lacquer at $10 \mathrm{wt} \%$ and $20 \mathrm{wt} \%$. The effects of the type and weight proportion of drying oils on the properties of OMRL coatings and films were investigated. The results showed that the drying oil acted as a diluent, reducing the viscosity and enhancing the workability of OMRL. Also, the addition of drying oil could potentially shorten the TF time, and an appropriate amount of drying oil, such as the addition of $20 \%$ DCO and LO, could speed up the HD of the RLs. The results also indicated that as more drying oils were blended, the hardness, mass retention, $T_{\mathrm{g}}$, tensile strength, abrasion resistance, and lightfastness of OMRL films was reduced, whereas the bending resistance, elongation at break, and impact resistance 
was enhanced. Gloss, in particular, could be greatly improved through the addition of more drying oil. Generally, the LO-modified RL had the highest film gloss, and DCO-modified refined lacquer had the shortest coating drying time. Otherwise, the other film properties were all similar amongst lacquers modified with the three drying oils. The OMRL containing $10 \%$ tung oil had better film flexibility and gloss than the RL films, and was more suitable for wood finishing. The OMRL containing $20 \%$ linseed oil had the highest gloss, lowest viscosity and a fast curing time, and is more suited to artistic applications. Further research to improve the lightfastness and shorten the curing time of oriental lacquer is need.

Author Contributions: Conceptualization, K.-T.L. and C.-W.C.; Methodology, K.-T.L. and C.-W.C.; Formal Analysis, H.-L.L. and C.-W.C.; Investigation, H.-L.L.; Writing-Original Draft Preparation, C.-W.C. and H.-L.L.; Writing-Review \& Editing, K.-T.L. and C.-W.C.; Supervision, K.-T.L.; Funding Acquisition, K.-T.L.

Funding: This research was funded by Ministry of Science and Technology, Taiwan, (No. 100-2313-B-005-020-MY3).

Conflicts of Interest: The authors declare no conflict of interest.

\section{References}

1. Niimura, N.; Miyakoshi, T. Structural Study of Oriental Lacquer Films During the Hardening Process. Talanta 2006, 70, 146-152. [CrossRef] [PubMed]

2. Bai, W.; Cai, L.; Zhuo, D.; Xu, Y.; Xue, H.; Chen, Q.; Lin, J. Resurrection of Dead Lacquer-Cupric Potassium Chloride Dehydrate $\left(\mathrm{K}_{2} \mathrm{CuCl}_{4} \cdot 2 \mathrm{H}_{2} \mathrm{O}\right)$ used as the Mimic Laccase. Prog. Org. Coat. 2014, 77, 431-438. [CrossRef]

3. Ma, X.-M.; Lu, R.; Miyakoshi, T. Recent Advances in Research on Lacquer Allergy. Allergol. Int. 2012, 61, 45-50. [CrossRef] [PubMed]

4. Honda, T.; Lu, R.; Sakai, R.; Ishimura, T.; Miyakoshi, T. Characterization and Comparison of Asian Lacquer Saps. Prog. Org. Coat. 2008, 61, 68-75. [CrossRef]

5. Lu, R.; Harigaya, S.; Ishimura, T.; Nagase, K.; Miyakoshi, T. Development of a Fast Drying Lacquer Based on Raw Lacquer Sap. Prog. Org. Coat. 2004, 51, 238-243. [CrossRef]

6. Lee, J.; Doh, J.-M.; Hahn, H.-G.; Lee, K.-B.; Lee, Y. Investigation of Asian Lacquer Films using ToF-SIMS and Complementary Analytical Techniques. Surf. Interface Anal. 2017, 49, 479-487. [CrossRef]

7. Kumanotani, J. Enzyme Catalyzed Durable and Authentic Oriental Lacquer: A Natural Microgel-printable Coating by Polysaccharide-Glycoprotein-Phenolic Lipid Complexes. Prog. Org. Coat. 1998, 34, 135-146. [CrossRef]

8. Kumanotani, J. Urushi (oriental lacquer)—A Natural Aesthetic Durable and Future-promising Coating. Prog. Org. Coat. 1995, 26, 193-195. [CrossRef]

9. Heginbotham, A.; Chang, J.; Khanjian, H.; Schilling, M.R. Some Observations on the Composition of Chinese Lacquer. Stud. Conserv. 2016, 61, 28-37. [CrossRef]

10. Karak, N. Vegetable Oil-Based Polymers: Properties, Processing and Applications; Woodhead Publishing: Oxford, UK, 2012; pp. 54-95.

11. Hutchinson, G.H. Some Aspects of Drying Oils Technology. J. Oil Colour Chem. Assoc. 1973, 56, 44-53.

12. Güner, F.S.; Yağci, Y.; Erciyes, A.T. Polmers from Triglyceride Oils. Prog. Polym. Sci. 2006, 31, $633-670$. [CrossRef]

13. Oldring, P.K.T.; Hayward, G. A Manual for Resins for Surface Coatings, 2nd ed.; Surfex: London, UK, 1987; pp. 49-63.

14. Tuman, S.J.; Chamberlain, D.; Scholsky, K.M.; Soucek, M.D. Differential Scanning Calorimetry Study of Linseed Oil Cured with Metal Catalysts. Prog. Org. Coat. 1996, 28, 251-258. [CrossRef]

15. Soucek, M.D.; Khattab, T.; Wu, J. Review of Autoxidation and Driers. Prog. Org. Coat. 2012, 73, 435-454. [CrossRef]

16. Ogunniyi, D.S. Castor Oil: A Vital Industrial Raw Material. Bioresour. Technol. 2005, 97, 1086-1091. [CrossRef] [PubMed]

17. Mcsharry, C.; Faulkner, R.; Rivers, S.; Shaffer, M.S.P.; Welton, T. The Chemistry of East Asian Lacquer: A Review of the Scientific Literature. Stud. Conserv. 2007, 52, 29-40. [CrossRef] 
18. Wan, Y.-Y.; Du, Y.-M.; Yang, F.-X.; Xu, Y.; Chen, R.-Z.; Kennedy, J.F. Purification and Characterization of Hydrosoluble Components from the Sap of Chinese Lacquer Tree Rhus Vernicifera. Int. J. Biol. Macromol. 2006, 38, 232-240. [CrossRef]

19. CNS 2810 Method of Test for Chinese Lacquer; CNS: Taipei, Taiwan, 1986.

20. CNS 3646 Method of Test for Edible Oils and Fats-Determination of Iodine Value; CNS: Taipei, Taiwan, 2009.

21. CNS 9007 Method of Test for Paints-Sampling and General Condition; CNS: Taipei, Taiwan, 1995.

22. Lu, R.; Honda, T.; Ishimura, T.; Nagase, K.; Miyakoshi, T. Study of A Naturally Drying Lacquer Hybridized with Organic Silane. Polym. J. 2005, 37, 309-315. [CrossRef]

23. ISO 1522 Paints and Varnishes_Pendulum Damping Test; ISO: Geneva, Switzerland, 2007.

24. JIS K 5400 Testing Methods for Paints; Japanese Standards Association: Tokyo, Japan, 1990.

25. ASTM D638 Standard Test Method for Tensile Properties of Plastics; ASTM International: West Conshohocken, PA, USA, 2014.

26. CNS 10756 K6800 Method of Test for Paints (Film Formability of Paints); CNS: Taipei, Taiwan, 1994.

27. Tamburini, D.; Sardi, D.; Spepi, A.; Duce, C.; Tinè, M.R.; Colombini, M.P.; Bonaduce, I. An Investigation into the Curing of Urushi and Tung Oil Films by Thermoanalytical and Mass Spectrometric Techniques. Polym. Degrad. Stab. 2016, 134, 251-264. [CrossRef]

28. Larsen-Badse, J.; Mathew, K.G. Influence of Structure on the Abrasion Resistance of a 1040-Steel. Wear 1969, 4, 199-205. [CrossRef]

29. Lu, R.; Kamiya, Y.; Kumamoto, T.; Honda, T.; Miyakoshi, T. Deterioration of Surface Structure of Lacquer Films Due to Ultraviolet Irradiation. Surf. Interface Anal. 2006, 38, 1311-1315. [CrossRef]

30. Liu, X.; Elmahdy, A.E.; Wildman, R.D.; Ashcroft, I.A.; Ruiz, P.D. Experimental Investigation and Material Modelling of Fresh and UV Aged Japanese Lacquer (Urushi). Prog. Org. Coat. 2011, 70, 160-169. [CrossRef]

31. Obataya, E.; Furuta, Y.; Ohno, Y.; Norimoto, M.; Tomita, B. Effects of Aging and Moisture on the Dynamic Viscoelastic Properties of Oriental Lacquer (Urushi) Film. J. Appl. Polym. Sci. 2002, 83, 2288-2294. [CrossRef]

(c) 2018 by the authors. Licensee MDPI, Basel, Switzerland. This article is an open access article distributed under the terms and conditions of the Creative Commons Attribution (CC BY) license (http:/ / creativecommons.org/licenses/by/4.0/). 